\title{
Breddat deltagande för studenter med funktionsnedsättning - En utmaning för den högre utbildningen
}

\author{
Lotta Anderson ${ }^{\mathrm{a}}$, Hanna Egard ${ }^{\mathrm{b} *}$, Camilla Nordgren ${ }^{\mathrm{c}}$ och Patricia Staaf $^{\mathrm{d}}$ \\ ${ }^{a}$ Institutionen för skolutveckling och lederskap, Malmö universitet; ${ }^{\mathrm{b}, \mathrm{c}}$ Institutionen för socialt arbete, \\ Malmö universitet; \\ ${ }^{\mathrm{d}}$ Centrum för akademiskt lärarskap, Malmö universitet.
}

\begin{abstract}
Frågor kring breddad rekrytering och breddat deltagande utgör en del av den sociala dimensionen av högre utbildning och är ett prioriterat område för det europeiska samarbetet. 2017 års förslag om att ändra i högskolelagen och vidga lärosätenas uppdrag till att aktivt främja ett brett deltagande gav upphov till en debatt bland såväl politiker som företrädare för lärosäten, vilken synliggjorde flera utmaningar, förhoppningar och farhågor. Föreliggande reflektion tar avstamp i denna debatt och fördjupar sig i frågor kring breddat deltagande för studenter med funktionsnedsättning. Syftet med reflektionen är att diskutera och reflektera kring vad breddat deltagande för denna målgrupp innebär och vilka krav det ställer på resurser, tillgänglighet, bemötande och attityder samt på högskolepedagogisk kompetensutveckling, kunskap om funktionsnedsättning och funktionshinder samt inkluderande pedagogik. Utgångspunkten för reflektionen är svensk forskning och pågående utvecklingsarbete om breddat deltagande för studenter med funktionsnedsättning samt författarnas erfarenhetsbaserade kunskaper om högskolepedagogisk undervisning och kompetensutveckling.
\end{abstract}

Nyckelord: breddat deltagande, breddad rekrytering, funktionsnedsättning, funktionshinder, inkluderande pedagogik, tillgänglighet, högskolepedagogik, pedagogiskt stöd

\section{INLEDNING}

Under 2017 kom ett förslag om en till synes liten förändring i I kap. $5 \$$ av högskolelagen (SFS I992:I434). Istället för att lärosätena aktivt skulle "främja och bredda rekryteringen till högskolan" föreslogs att lärosätena skulle få i uppdrag att aktivt främja "ett brett deltagande i utbildningen" (Utbildningsdepartementet, 20I7). Genom ändringen skulle lärosätenas uppdrag vidgas och omfatta såväl arbete för en breddad rekrytering som att ge studenter möjlighet att genomföra och fullfölja sin utbildning (breddat deltagande). Vidare innebar förslaget en utvidgning av målgruppen för breddat deltagande och "att personer frän olika delar av landet oavsett kön, könsöverskridande identitet eller uttryck, etnisk tillhörighet, religion eller annan trosuppfattning, funktionsnedsättning, sexuell läggning, ålder eller social bakgrund" skulle söka, påbörja och fullfölja en högskoleutbildning (Utbildningsdepartementet, 2017 s. 6). Förslaget på ändring i högskolelagen presenterades, debatterades och drogs sedan - efter kritik från flera lärosäten - tillbaka. Den främsta kritiken i remissvaren rörde att förslaget var otydligt och skulle kunna innebära att kvaliteten sänktes samt att förslaget inte omfattade någon resursförstärkning för det vidgade

*Författarkontakt: hanna.egard@mah.se 
uppdraget. Ministern för högre utbildning och forskning, Helen Hellmark Knutsson, höll dock fast vid behovet av att stärka arbetet med breddat deltagande. I beslutet att dra tillbaka förslaget hänvisade hon till kommande resursfördelningsutredning samt poängterade vikten av kvalitet i utbildningen (Helmerson, 20I7).

Processen och debatten kring den föreslagna ändringen i högskolelagen aktualiserar frågor kring vad målet med breddat deltagande är, vilket ansvar lärosätena har och även vilka utmaningar breddat deltagande är förknippat med för lärosäten, studenter och universitetslärare. I denna reflektion kommer vi att avgränsa oss till en av målgrupperna för breddat deltagande, nämligen personer med funktionsnedsättning. För denna målgrupp finns styrdokument och rättslig reglering gällande rätt till utbildning, rumslig och pedagogisk tillgänglighet samt förbud mot diskriminering. ${ }^{\mathrm{I}}$ Vidare finns särskilda statliga medel avsatta för stöd i studiesituationen som lärosätena kan söka. ${ }^{2}$ Därmed skulle man kunna tro att gruppens behov är väl tillgodosedda, men det bör betonas att vare sig regelverk eller medel för stöd i studiesituationen är detsamma som att det finns pedagogisk kompetens eller kompetens att anpassa lärandemiljön. Nationell statistik från 2016 visar att strax över 13 ooo studenter har varit i kontakt med en samordnare vid lärosätesenheterna som har till uppdrag att samordna individuellt pedagogiskt stöd för studenter med funktionsnedsättning. Merparten av de studenter som erhåller pedagogiskt stöd har dyslexi, neuropsykiatriska funktionsnedsättningar och psykisk ohälsa (Källoff, Thomasson, Wahlgren \& Andersson, 20I5).

Syftet med denna reflektion är att belysa lärosätenas utmaningar med att ge möjlighet för studenter med funktionsnedsättning att genomföra en högre utbildning. Vidare vill vi diskutera och reflektera kring vad breddat deltagande av studenter med funktionsnedsättningar och/ eller psykisk ohälsa innebär och vilka krav det ställer på resurser, tillgänglighet, bemötande och attityder samt på högskolepedagogisk kompetensutveckling och kunskap om funktionsnedsättning, funktionshinder och inkluderande pedagogik. Med funktionsnedsättning avses här en nedsättning av fysisk, psykisk eller kognitiv funktionsförmåga (Socialstyrelsen, 20II). Funktionshinder avser den begränsning som en funktionsnedsättning medför för personen i relation till omgivningen (ibid.)

\section{BAKGRUND}

Bakgrunden till att svenska lärosäten ska arbeta aktivt för att främja breddad rekrytering går att finna bland annat i propositionen 200I/O2:15 "Den öppna högskolan" (Utbildningsdepartementet, 200I) men också i Bolognasamarbetet (Universitets- och högskolerådet [UHR], 20I6) och i efterföljande reformer. Intentionen med "Den öppna högskolan" var att främja en breddad rekrytering och därigenom minska den sociala och etniska snedrekryteringen samt öka rekryteringen till högre utbildning genom det så kallade 50 -procentsmålet (d.v.s. att 50 procent av en årskull ska ha börjat högre utbildning vid 25 års ålder). Den senare målsättningen är inte längre aktuell. Däremot lever den politiska ambitionen om en breddad rekrytering och en högre utbildning som speglar samhällets mångfald kvar (Utbildningsdepartementet, 20I7). Samma intention återfinns inom Bolognasamarbetet där det anges att sammansättningen av studenter som antas till, deltar i och fullföljer högre utbildning på alla nivåer ska spegla samhällets mångfald (London Communiqué, 2007). Denna så kallade "sociala dimension av högre utbildning" är ett prioriterat område inom det europeiska samarbetet kring högre utbildning. Sverige och andra länder som deltar i samarbetet åtar sig att bredda deltagandet, "to widen participation". Vidare ska det finnas stöd för studenter med olika lärstilar, vilket formuleras som att länderna förbinder sig att "support institutions that provide relevant learning activities in appropriate contexts for different types of learners, including lifelong learning". (Yerevan Communique, 
2015 s.2). Prioriteringarna inom det europeiska samarbetet återspeglas i de svenska lagarna, förordningarna och regleringsbreven vilket i sin tur får följder för lärosätena.

I ambitionen att anpassa och ge likvärdiga möjligheter är det angeläget att inte blunda för risken att krav sänks eller förändras och därmed glider ifrån de uppsatta lärande- och examensmålen för kurser och utbildningar. Detta är en ängslan som inte endast finns hos politiker (Björklund \& Nylander, 2017, I3 augusti; Malmberg, 2017, I8 augusti; Strand, 2017, 24 augusti), utan också bland högskole- och universitetslärare (Aldrin, 20I6) som möter utmaningen att förändra sin undervisning i mötet med nya studentgrupper. Detta gör det angeläget att på allvar diskutera pedagogisk utveckling i syfte att med bibehållen kvalitet kunna inkludera fler i högre utbildning.

Som ansvariga för pedagogiskt utvecklingsarbete inom högre utbildning och med lång erfarenhet av högskolepedagogisk undervisning har författarna sökt kunskap om hur vi kan utveckla pedagogiken och skapa arbets- och examinationsformer som är tillgängliga för alla studenter och främjar breddat deltagande. Insikten om att fältet är underbeforskat i en svensk kontext ledde fram till en konferens för och med olika intressenter inom området. Konferensen Breddat deltagande: Perspektiv på dagens högre utbildning och funktionsnedsättning ${ }^{3}$ genomfördes i december 2016 som ett samarbete mellan Sydsvenskt centrum för forskning om funktionsnedsättning och funktionshinder (Harec) och Nationellt nätverk för breddad rekrytering och breddat deltagande inom högre utbildning (Include). Exempel på pedagogiskt utvecklingsarbete som presenterades på konferensen och tidigare forskning om lärosätenas arbete med breddat deltagande för studenter med funktionsnedsättning utgör tillsammans med vår erfarenhetsbaserade kunskap grunden för denna reflektion.

\section{STUDENTER MED FUNKTIONSNEDSÄTTNING}

Det finns ingen klar bild över hur många personer med funktionsnedsättning som har genomgått, eller har försökt att genomgå, en högre utbildning då det i Sverige inte finns något register över studenter med funktionsnedsättning. Om den nationella statistiken över hur många studenter som ansöker om pedagogiskt stöd vid funktionsnedsättning ${ }^{4}$ också kan användas för att bedöma hur många studenter som har en funktionsnedsättning är oklart, eftersom det inte är säkert att alla studenter med funktionsnedsättning efterfrågar stöd eller känner till att hen kan ansöka om pedagogiskt stöd (Eriksson Gustavsson, 20II; Eurostudent V, Universitets- och högskolerådet, 20I5; Källoff et al., 20I5). Vidare är det inte klarlagt hur vanligt det är att funktionsnedsättningen medför hinder och behov av stöd i studiesituationen. Det finns inte heller någon enhetlig definition av vad som räknas som en funktionsnedsättning (SCB, 20I6), vilket sammantaget försvårar fastställandet av antalet studenter som har en funktionsnedsättning.

De uppgifter som finns att tillgå baseras på studenters självskattning av om de har en funktionsnedsättning. I en enkätundersökning som genomfördes av Eurostudent år 2015 anger I7 procent, av de totalt I433 svenska studenter som besvarar enkäten, att de har en funktionsnedsättning av något slag. Två tredjedelar av dessa anger att funktionsnedsättningen utgör ett hinder i studiesituationen. Bland studenter med psykiska besvär och/eller neuropsykiatrisk funktionsnedsättning anger 9 av Io att nedsättningen utgör ett stort hinder i studierna (Eurostudent V, UHR, 20I5). Uppgifterna kan tolkas som att funktionsnedsättningen påverkar studiesituationen, vilket torde variera beroende på vilken typ av funktionsnedsättning det rör sig om. En annan möjlig tolkning är att de studenter som inte upplever att funktionsnedsättningen medför hinder har erhållit stöd och anpassningar som bidragit till att eventuella hinder för att bedriva studier har undanröjts. 


\section{LÄROSÄTENAS ERFARENHETER AV BREDDAT DELTAGANDE FÖR STUDENTER MED FUNKTIONSNEDSÄTTNING}

Universitets- och högskolerådet, UHR, har på uppdrag av regeringen gjort en kartläggning och analys av lärosätenas arbete med breddad rekrytering och breddat deltagande (20I6). Rapporten belyser särskilt hur lärosätena arbetar med individuellt pedagogiskt stöd. Lärosätena anger i kartläggningen att de har rutiner för att $\mathrm{i}$ ett tidigt skede fånga upp studenter i behov av stöd, allt ifrån språkstöd till stöd vid funktionsnedsättning. Processerna ser olika ut men för stödåtgärder för personer med funktionsnedsättning krävs alltid intyg på själva nedsättningen. UHR (2016) konstaterar att om högskolemiljön inte är anpassad kan eventuella sökande avstå från att söka till lärosätet. Likaså framhålls vikten av att studenter har god framförhållning inför att påbörja studier, vilket kan krocka med lärosätenas administrativa system där sådan framförhållning är mera sällan förekommande. Stödåtgärderna som kartlagts utgörs i huvudsak av anpassad examination, mentorskap/anteckningsstöd, utökad handledning, tillgängliggjorda läromedel och tekniska hjälpmedel. Anpassad fysisk studiemiljö anges vara en mindre vanlig stödåtgärd för studenter med funktionsnedsättning.

En enkätstudie vid Göteborgs universitet (n=I48I) synliggör emellertid att långt ifrån alla universitetslärare har kännedom om stödfunktioner för studenter med funktionsnedsättning och att det finns stora skillnader mellan olika fakulteter (Larsson, 2016). Cirka hälften av de tillfrågade lärarna svarar att de känner till att det finns en samordningsfunktion för studenter med funktionsnedsättning. På frågan om respondenterna har kunskap om rutiner och handläggningsordning för studenter med funktionsnedsättning svarar knappt hälften att de känner till detta. När det gäller pedagogiken anger mindre än hälften av lärarna att de har de pedagogiska förutsättningarna/verktygen/resurserna för att undervisa och examinera studenter med funktionsnedsättningar. Tre färdedelar anger vidare att de skulle vilja ha fortbildning inom området (ibid.).

I studier som baseras på fokusgruppsintervjuer med universitetslärare framkommer att lärarna ställs inför flera dilemman när de ska ge pedagogiskt stöd till och anpassa examinationer för studenter med funktionsnedsättning (Eriksson Gustavsson \& Holme, 2009). I grunden handlar dessa dilemman om vad likabehandling och lika villkor innebär i praktiken och hur lärarna ska agera för att behandla alla lika, ställa samma krav på alla studenter och samtidigt ta hänsyn till studenternas olika förutsättningar. Vidare framkommer att universitetslärarna kan vara rädda för att bli anklagade och anmälda för diskriminering. De upplever ett behov av att prata om hur de ska utforma kompensatoriskt stöd och anpassningar samt hur de ska samtala med studenter med sådana behov. De framhåller också betydelsen av att medstudenter får information och kunskap om vilket behov av stöd och anpassning som deras studiekamrater med funktionsnedsättningar behöver. Flera av universitetslärarna som intervjuats är medvetna om att det finns olika pedagogiska vägar och former för examination för att uppnå samma mål. Samtidigt upplever de en oro för att examinationen inte blir rättvis om formen för examination varierar. En del av de intervjuade universitetslärarna menar att det är möjligt att anpassa arbetsformerna och ändå nå upp till lärandemål och examensmål. Andra frågar sig om anpassningarna kan påverka kvaliteten på utbildningen och om alla professionsutbildningar är lämpliga för studenter med funktionsnedsättning (ibid.). Berndts (20I5) studie "Universitetslärares erfarenheter av stöd till studenter med funktionsnedsättning" bekräftar dessa frågeställningar kring vem som är lämplig för ett yrke, men de intervjuade i Berndts studie menar också att bilden av vem som är lämplig eller ej för ett yrke behöver utmanas såväl inom utbildningen som på arbetsplatserna. 
När det gäller arbetsbördan upplever en del universitetslärare att den ökar om de har studenter med funktionsnedsättning i sina undervisningsgrupper och att de inte får full kompensation för detta merarbete (Eriksson Gustavsson \& Holme, 2009). Det extra arbetet består i tidigarelagt förarbete och planering av kurser och examination samt möten med andra kollegor och studenter. En del av de intervjuade menar att bristen på resurser kan medföra att studenterna inte erhåller det stöd de har rätt till. Andra universitetslärare som deltar i studien upplever å andra sidan inte att det är förknippat med något merarbete att undervisa studenter med funktionsnedsättning utan menar att de blir hjälpta av de stödfunktioner som finns på lärosätet för att utforma och genomföra anpassningar av olika slag (ibid.). De intervjuade universitetslärarna i Berndts (2OI5) studie betonar vikten av samverkan och samordning av det pedagogiska stödet för att lärarna ska få stöd i sitt arbete och studenterna stöd i sina studier.

\section{DISKUSSION}

Syftet med föreliggande reflektion är att belysa vad breddat deltagande för studenter med funktionsnedsättning innebär och vilka krav det ställer på resurser, kunskap och kompetens vid lärosätena.

Den diskussion som följde efter förslaget om ändring i högskolelagen, från breddad rekrytering till breddat deltagande, kan ses som en signal om behovet av att diskutera hur breddat deltagande bäst kan uppnås och pedagogiken i högre utbildning utvecklas (Helmerson, 20I7, I december). Förslaget har från politiskt håll tolkats som att kraven på både tillträde och godkänd utbildning ska sänkas (Björklund \& Nylander, 20I7, I3 augusti; Malmberg, 2017, I8 augusti; Strand, 2017, 24 augusti). En annan ståndpunkt, som både framförts av politiker och företrädare för den högre utbildningen, är att lärosätenas uppdrag skulle bli förtydligat genom den föreslagna ändringen i Högskolelagen (Olsson, 2017, IO augusti; Tham, 2017, I6 augusti).

Vår erfarenhet är att breddat deltagande för studenter med funktionsnedsättning är möjligt att uppnå utan att ändra lärandemål, sänka examensmål eller krav på behörighet. Det som behöver förändras är uppfattningen om och attityder till studenter med funktionsnedsättning inom den högre utbildningen, vilket också uppmärksammats av Sveriges förenade studentkårer (SFS, 20I5). Vidare behöver den högre utbildningens uppdrag och ansvar förtydligas när det gäller denna målgrupp för breddat deltagande. Utgångspunkten för den högre utbildningen bör vara att människor med funktionsnedsättning utgör en del av mångfalden i såväl befolkningen som i studentpopulationen. Den högre utbildningens lokaler, digitala miljöer, administration och pedagogik behöver med andra ord utformas med studenter med funktionsnedsättning i åtanke. Med utgångspunkt i tidigare forskning, men även i egna erfarenheter av högskolepedagogisk undervisning och utvecklingsarbete, vill vi belysa att breddat deltagande av studenter med funktionsnedsättning kräver ökade resurser, förändrade attityder och ökad kunskap och kompetens inom den högre utbildningens samtliga funktioner.

Tidigare forskning pekar på att samordningen av det individuella pedagogiska stödet behöver utvecklas och att kunskap om det pedagogiska stödet behöver spridas till såväl universitetslärare som studenter (Berndt, 20I5; Eriksson Gustavsson, 20II; Källoff et al., 20I5; Larsson, 2016). Vidare framkommer att kursadministration, undervisning och examination av kurser där en eller flera av studenterna har en funktionsnedsättning kan innebära ett merarbete för universitetslärarna (Eriksson Gustavsson \& Holme, 2009). Detta merarbete behöver universitetslärarna bli kompenserade för. Då utgångspunkten bör vara att studenter med funktionsnedsättning utgör en del av studentpopulationen bör timmar för examination och kursadministration utökas generellt, istället för att som idag tillföras först om studenter med funktionsnedsättning 
erhåller individuellt pedagogiskt stöd. Ett generellt tillägg på alla kurser och utbildningar skulle också tydliggöra att alla universitetslärare vid behov förväntas anpassa undervisnings- och examinationsformer och även samverka med stödenheter för studenter med funktionsnedsättning.

Som framhålls i tidigare forskning kan universitetslärare ställas inför svåra övervägningar när de ska anpassa undervisning och examination efter studentens funktionsnedsättning och samtidigt bibehålla kunskapskraven (Eriksson Gustavsson \& Holme, 2009). Våra erfarenheter från undervisning och examination i studentgrupper, där upp mot Io procent har en funktionsnedsättning, visar att det behövs utrymme och arenor för att diskutera dessa dilemman. Rädslan att sänka kraven kan utifrån våra erfarenheter till och med resultera i att de faktiskt höjs för enskilda studenter då dessa individer särskilt uppmärksammas och därmed riskerar att bli mera granskade än andra studenter. I sammanhanget är det dock viktigt att påpeka att breddat deltagande inte ska förväxlas med ıoo-procentig genomströmning, utan att krav som ställs ska vara likvärdiga även om undervisning och examinationsformer anpassas efter studentens funktionsnedsättning. Att universitetslärare får mer kunskap och erhåller kompetensutveckling samt att ledningen driver frågor kring breddat deltagande för studenter med funktionsnedsättning (Berndt, 2015; Eriksson Gustavsson \& Holme, 2009) framhålls som centralt i tidigare forskning. Vår utgångspunkt är att högskolepedagogiken behöver utvecklas för att skapa en inkluderande högre utbildning. Detta kräver ocksa ökade resurser för att kunna genomföras. Istället för att se lösningar för enskilda studenter som en extra belastning för den enskilde läraren, alternativt anordna särskilda kurser för studenter med funktionsnedsättning, bör fokus läggas på att utveckla den generella pedagogiken på lärosätena så att utbildningen görs mer tillgänglig för samtliga studenter.

De högskolepedagogiska enheterna vid landets högskolor och universitet har en roll att fylla som arena för diskussion om lärandets förutsättningar och högskolelärares möjligheter att bedriva en inkluderande pedagogik. Utöver att bidra till kompetensutveckling kring regelverk och pedagogiska metoder är frågor om förhållningssätt och bemötande centrala i allt högskolepedagogiskt utvecklingsarbete. Det handlar inte enbart om den individuelle lärarens kompetens och kompetensutveckling utan också om en institutionell förflyttning. Uppmärksamhet måste riktas mot hur lärosätena definierar kvalitet och värderar pedagogiskt arbete. Det innebär också att de högskolepedagogiska enheternas målgrupp måste utvidgas till att omfatta personer i lednings- och verksamhetsstödjande positioner, eftersom många av de beslut som rör tillgänglighetsfrågor fattas långt från den enskilde läraren. De pedagogiska enheterna behöver i detta arbete samarbeta med annan expertis.

Avslutningsvis redovisas här ett par exempel på pedagogiska arbetssätt som syftar till att främja breddat deltagande. En seminarieserie som genomfördes vid Malmö universitet (dåvarande Malmö högskola) under 2014 kan tjäna som en modell för hur ett samarbete mellan pedagogiska enheter och högskolelärare, administration, lokalansvariga och studenthälsan kan utformas. Inom ramen för seminarieserien informerades om styrdokument och stödfunktioner visavi studenter med funktionsnedsättning och det skedde ett utbyte av erfarenheter mellan högskolans olika personalkategorier. Generell och specifik tillgänglighet problematiserades i relation till deltagarnas egna erfarenheter och olika svårigheter som anställda mött i den egna praxisen identifierades och diskuterades. Det konstaterades att ett bemötande som präglas av öppenhet och respekt i en väl anpassad fysisk miljö medför färre krav på särlösningar. Vidare framkom att det är en pedagogisk utmaning att utforma en lärandemiljö som fungerar inkluderande och gör alla studenter delaktiga. Innehållet i seminarieserien fokuserade även på olika specifika stödfunktioner som erbjuds vid Malmö universitet samt på generella tillgänglighetsfrågor. 
Sammanfattningsvis ledde seminarieserien fram till vidareutveckling av ett informationsmaterial om att undervisa tillgängligt, främst avsett för undervisande lärare (Malmö universitet, 20I7).

Ett annat exempel kan hittas i Häggblom (2015). Här argumenteras för konceptet universell design för lärande (Universal design for Learning, UDL), som utgår från uppfattningen att en lösning inte kan passa alla. I stället behövs variation och alternativa metoder för hur kursinnehållet förmedlas, för hur studenter demonstrerar sin kunskap och för hur engagemang och motivation skapas (CAST, 20I2).5 Försöksprojekt kring UDL pågår exempelvis vid Högskolan Kristianstad (Häggblom, 20I5). Samtidigt som UDL erbjuder sätt att underlätta för såväl lärare som studenter behöver de strukturella förutsättningarna för undervisning i heterogena studentgrupper diskuteras så att resursbrist inte utgör ett hinder för anpassad undervisning (Eriksson Gustavsson \& Holme, 2009). Resursbrist kan avse särskild utrustning men också lärartid. Stora studentgrupper kan också vara en utmaning.

Som ett komplement till UDL kan Sveriges lärosäten även erbjuda kurser som förbereder för högre studier. Ett exempel är kursen "Högre utbildning - En möjlighet för alla” som hämtat upplägget och innehållet från konceptet "Supported Education". Konceptet vänder sig främst till personer med psykiatrisk funktionsnedsättning och har en rehabilitativ ansats där studenten ges stöd och verktyg för att uppnå sitt utbildningsmål (Mowbray et al., 2005). Kursen genomfördes på deltid vid Malmö universitet (dåvarande Malmö högskola) och vände sig till presumtiva studenter med funktionsnedsättning, t.ex. psykiatrisk diagnos. Kursinnehållet utgjordes av a) teoretiskt samhällsperspektiv på funktionshinder, b) att vara student/studentrollen, c) karriärdrömmar och d) grupprocesser. Nordgren och Ohlsson (2016) bedrev följeforskning under kursens gång och intresserade sig för studentens hela studiesituation. Just vikten av att ha en helhetssyn på studenten befästes i det teoretiska begreppet "sense of belonging" som användes $\mathrm{i}$ studien. Studenterna i studien framhöll vikten av att lära sig bemästra sina styrkor och svagheter och att förstå sin funktionsnedsättning i relation till kravet på studieprestation. Att inse behovet av dygnsrutiner och en fungerande miljö vid självstudier framkom som särskilt avgörande. Att identifiera sig som student och lärande individ visade sig vara utmanande. Andra aspekter som uppmärksammades var svårigheter med samhällets olika system (t.ex. sjukskrivningssystem och synen på vad som definieras som rehabilitering) som kan krocka och omöjliggöra deltagande i kursen.

Avslutningsvis kan uppmärksammas att även om formuleringen i högskolelagen förblir oförändrad har UHR (20I6) konstaterat att flera lärosäten redan idag arbetar som om uppdraget inkluderar även breddat deltagande. Detta synliggörs också av ovanstående exempel på pedagogiskt utvecklingsarbete. I sitt yttrande gällande förslaget om ändring i högskolelagen föreslår UHR att regeringen ska ge dem i uppdrag att regelbundet följa upp lärosätenas arbete med breddad rekrytering och breddat deltagande. ${ }^{6,7}$ Ett sådant uppdrag kan i kombination med ökade resurser till lärosätena och utbyte av forskningsresultat, erfarenheter och kunskaper om inkluderande pedagogik bidra till ett verkligt breddat deltagande för studenter med funktionsnedsättning.

\section{FÖRFATTARPRESENTATIONER}

Lotta Anderson är filosofie doktor i specialpedagogik, lektor och forskare i specialpedagogik och verksam vid institutionen för skolutveckling och ledarskap vid Malmö universitet. Lotta är koordinator för magister/masterutbildningar i pedagogik, specialpedagogik och ämnesdidaktik och har lång erfarenhet av högskolepedagogiskt arbete inom de specialpedagogiska programmen. Forskningsintresse är bl.a. studenter med funktionsnedsättning i högre utbildning, alternativa kommunikationsformer och pedagogiskt arbete i särskola. 


\section{L. Anderson et al.}

Hanna Egard är filosofie doktor i socialt arbete och var föreståndare för Harec under perioden 20I2-20I6. Hon forskar om tillgänglighet, är lektor i socialt arbete med inriktning handikapp- och rehabiliteringsvetenskap och verksam vid institutionen för socialt arbete vid Malmö universitet. Hanna har lång erfarenhet av högskolepedagogiskt arbete i studentgrupper där en hög andel studenter har funktionsnedsättning och/ eller psykisk ohälsa.

Camilla Nordgren är filosofie doktor i rehabiliteringsteknik, forskare och lektor i socialt arbete med inriktning handikapp- och rehabiliteringsvetenskap och verksam vid institutionen för socialt arbete vid Malmö universitet. Camilla har haft uppdrag som pedagogiskt ansvarig och har i undervisningssammanhang bred erfarenhet av att möta studenter med funktionsnedsättning. Forskningsintresse är bl.a. vardagsliv och högskolestudier för personer med funktionsnedsättning.

Patricia Staaf är filosofie licentiat i svenska språket och adjunkt i svenska som andraspråk. Sedan 2013 är hon föreståndare för Malmö universitets högskolepedagogiska verksamhet, Centrum för akademiskt lärarskap. Patricia har bred erfarenhet av arbete med frågor kring breddad rekrytering och breddat deltagande och ett särskilt intresse för hur detta omsätts inom högskolepedagogiken.

\section{NOTER}

I. FN:s konvention om rättigheter för personer med funktionsnedsättning, Regeringens proposition (2016/17:188) Nationella mål och inriktning för funktionshinderpolitiken, Förordning (2001:526) om de statliga myndigheternas ansvar för genomförande av funktionshinderpolitiken, Diskrimineringslag (2008:567).

2. Högskoleförordning (1993:I00) reglerar tillgång till hälsovård, studiesocialt stöd och en god studiemiljö. Förordningen (2011:1163) om statsbidrag för särskilt utbildningsstöd reglerar bidrag för att anställa stödpersoner för studenter. Regeringens årliga regleringsbrev för universitet och högskolor reglerar de nationella medlen för individuellt pedagogiskt stöd som samordnas av en särskild enhet vid Stockholms universitet.

3. https://www.mah.se/Nyheter/Kalender/Konferens-Breddat-deltagande 2018-03-22

4. Andelen studenter som söker individuellt pedagogiskt stöd för studenter med funktionsnedsättning har ökat kraftigt och nästan fördubblats sedan 2009 då 7500 studenter sökte stöd fram till år 2016 då antalet var 13000 , http://www.scb.se/hitta-statistik/statistik-efter-amne/levnadsforhallanden/levnadsforhallanden/undersokningarna-av-levnadsforhallanden-ulf-silc/pong/tabell-och-diagram/statistik-om-personermed-funktionsnedsattning/tabeller-20142015/

5. http://www.udlcenter.org/aboutudl/udlguidelines 2018-03-14

6. https://www.uhr.se/om-uhr/nyheter/2017/uhr-vill-folja-upp-hogskolornas-arbete-med-breddatdeltagande/2017-10-23

7. UHR:s yttrande Dnr: 1.2.3-00572-2017 https://www.uhr.se/globalassets/_uhr.se/publikationer/yttranden/ $2017 /$ yttrande-brett-deltagande-i-hogskoleutbildning.pdf

\section{REFERENSER}

Aldrin, V. (2016). Frågebaserad professionsetik eller etiska riktlinjer i högre utbildning? Fungerar SULF:s yrkesetiska riktlinjer i relation till breddad rekrytering och deltagande, eller är det dags för en ny form av yrkesetik i högre utbildning? Högre utbildning, 6 (2), 109-119, https://hogreutbildning.se/index. $\mathrm{php} / \mathrm{hu}$

Berndt, I. (2015). "Stöd i högre utbildning" Universitetslärares erfarenheter av stöd till studenter med funktionsnedsättning. Högskolan i Jönköping: Högskolan för lärande och kommunikation.

Björklund, J., Nylander, L. (2017, 13 augusti). Den rödgröna kravlösheten hotar kvaliteten i högskolan. Dagens Nyheter. Från https://www.dn.se/debatt/den-rodgrona-kravlosheten-hotar-kvaliteten-i-hogskolan/

Center for Applied Special Technology (CAST) (2012). Universal design for Learning Guidelines version 2.0. Från http://www.udlcenter.org/aboutudl/udlguidelines.

Eriksson Gustavsson, A-L. (2011). "Det är tufft att plugga... men jag känner att jag klarar det”. En studie om akademiska studier och skriftspråkliga svårigheter. Forskningsrapport LiU-PEK-R-257. Linköpings universitet: Institutionen för beteendevetenskap och lärande.

Eriksson Gustavsson, A-L. \& Holme, L. (2009). Att göra olika lika - universitetslärares uppfattningar om och erfarenheter av undervisning av funktionshindrade studenter. Forskningsrapport LiU-PEK-R-254. Linköpings universitet: Institutionen för beteendevetenskap och lärande. 
Eurostudent V, Universitets- och högskolerådet (2015). Från https://www.uhr.se/globalassets/_uhr.se/ lika-mojligheter/eurostudent/eurostudentv-funk-150624.pdf

Helmerson, K. (2017, 1 december). Regeringen backar frän kritiserat högskoleförslag. Sveriges Radio 2017-1201 . Från https://sverigesradio.se/sida/artikel.aspx ?programid=101\&artikel=6833502

Häggblom, P. (2015). Universell design för lärande - konceptet för ett paradigmskifte där vi anpassar lärosäten och inte studenter. Lärarlärdom 45-52. Växjö: Linneuniversitetet.

Källoff, K., Thomasson, A., Wahlgren, L. \& Andersson, C. (2015). Hur mår våra studenter? Studenthälsans undersökning om studiemiljö, psykisk hälsa, alkohol och drogvanor samt sexuell hälsa hos Malmö högskolas studenter. Malmö högskola: Studenthälsan.

Larsson, C. (2016). Högre utbildning och inkluderande undervisning "Studenten kan bidra med något eget något viktigt". En kartläggning av inkluderande undervisning vid Göteborgs universitet. Göteborgs universitet.

London Communiqué (2007). Towards the European Higher Education Area: responding to challenges in a globalised world. London: European Commission.

Malmberg, B. (2017, 18 augusti). Äventyrad kvalitet. Uppsala Nya Tidning, 5.

Malmö universitet (2017). Undervisa tillgängligt. Från https://www.mah.se/upload/FAKULTETER/Broschyr\%20unvervisa\%20tillg\%c3\%a4ngligt.pdf

Mowbray, C. T., Collins, M. E., Bellamy, C. D., Megivern, D. A., Bybee, D., Szilvagyi, S. (2005). Supported education for adults with psychiatric disabilities: an innovation for social work and psychosocial rehabilitation practice. Social Work 50(1), 7-20. https://doi.org/10.1093/sw/50.1.7

Nordgren, C. \& Ohlsson, L. (2016). New paths to education and working life through education and rehabilitation. In M. Hill, A. Hudson, S. Mckendry, N. Raven, D. Saunders, T. Ward. (Ed.), Closing the Gap: Bridges for Access and Lifelong Learning (pp. 145-161). University of East London: FACE.

Olsson, B. (2017, 10 augusti). Klass bör intressera liberaler. Sydsvenskan. Från https://www.sydsvenskan. se/2017-08-10/klass-bor-intressera-liberaler

SCB (2016). Välfärd nr 4/2016. Statistik om välfärd, arbetsmarknad, utbildning och befolkning. Från https:// www.scb.se/contentassets/d295177d048f466ca76389b1b960bbe5/le0001_2016k04_ti_a05ti1604. pdf

SFS 1992:1434. Högskolelag. Stockholm: Utbildningsdepartementet.

Socialstyrelsen (2011). Socialstyrelsens termbank. Från http://termbank.socialstyrelsen.se

Strand, T. (2017, 24 augusti). Breddat deltagande sänker inga krav. Uppsala Nya Tidning. Från http://www. unt.se/asikt/debatt/breddat-deltagande-sanker-inga-krav-4735694.aspx

Sveriges Förenade Studentkårer (SFS) (2015). Agenda: pedagogik Hur skapar vi förutsättningar för god undervisning? En undersökning frä Sveriges förenade studentkärer. Från https://www.sfs.se/sites/default/ files/agenda_pedagogik_alla_fattar_utom_jag.pdf

Tham, K. (2017, 16 augusti). En satsning på breddat deltagande bör inte handla om att sänka kraven på studenterna. Sydsvenskan. Från https://www.sydsvenskan.se/2017-08-16/en-satsning

Universitets- och högskolerådet (2016). Kan excellens uppnås $i$ homogena studentgrupper? Stockholm: Universitet- och högskolerådet. Från https://www.uhr.se/globalassets/_uhr.se/publikationer/2016/ uhr-kan-excellens-uppnas-i-homogena-studentgrupper.pdf

Universitets- och högskolerådet (2018). Bolognaprocessen. Från https://www.uhr.se/internationella-mojligheter/Bolognaprocessen/.

Utbildningsdepartementet (2001). Den öppna högskolan: om regeringens politik för högre utbildning. Proposition 2001/02:15. Stockholm: Regeringskansliet. Utbildningsdepartementet.

Utbildningsdepartementet (2017). Promemoria Brett deltagande i högskoleutbildning dnr: U2017/03082/ $\mathrm{UH}$.

Yerevan Communique (2015). European Higher Education Area (EHEA). Från http://bologna-yerevan 2015.ehea.info/files/YerevanCommuniqueFinal.pdf 